\title{
Mechanical Insufflation-Exsufflation to Improve Secretion Clearance During Invasive Ventilation
}

An effective clearing of the airways requires a balance between the production of respiratory secretions and their removal through the mucociliary escalator. For patients in the ICU, both sides of the balance can be impaired. Patients who are invasively ventilated frequently present impaired airway clearance for several reasons: the volume of respiratory secretions can be increased from infection, repeated aspirations, and other clinical factors. Moreover, endotracheal tubes or tracheostomy hinder glottis closure, which is the second phase of a cough maneuver (which occurs after inhaling near the total lung capacity and before contracting the abdominal muscles). It also reduces mucociliary clearance by increasing mucus volume retention below the artificial airway. In addition, prolonged immobility during invasive ventilation facilitates secretion retention and atelectasis. Accordingly, optimizing the management of airway clearance in the ICU includes detection of weak cough ${ }^{1,2}$ and carrying out methods that aim at enhancing the efficacy of cough, including secretion removal by physical airway clearance techniques. ${ }^{3}$

In patients who are invasively ventilated, endotracheal tube suctioning is the most common technique, ${ }^{3}$ but it may induce a false sense of efficiency. Indeed, tracheal suctioning is mostly effective in clearing secretions that pool at the end of the tracheal tube and the proximal airways. Moreover, besides the discomfort reported by patients, this invasive procedure carries a number of risks, including infection, trauma, bleeding, cardiovascular instability, hypoxemia, and increased intracranial pressure. ${ }^{3}$ Therefore, preceding endotracheal tube suctioning by the application of airway clearance techniques can increase efficiency by moving secretions from the periphery toward the central airways. This is also liable to prevent complications such as atelectasis, bronchitis, and pneumonia. ${ }^{3}$ The most commonly used techniques followed by tracheal suctioning are positioning, mobilization, manual hyperinflation, percus-

The authors have disclosed no conflicts of interest.

Correspondence: Frédéric Lofaso MD PhD, Services de Physiologie et Explorations Fonctionnelles, Hôpital Raymond Poincaré, AP-HP, 92380 Garches, France. E-mail: f.lofaso@rpc.aphp.fr.

DOI: $10.4187 /$ respcare .06700 sion, vibration, cough, and various breathing exercises. Despite a paucity of controlled studies for assessing objectively the effectiveness, these techniques are considered as standard of care in the ICU or at home. ${ }^{4}$

See the Original Study on Page 1471

Mechanical insufflation-exsufflation, which is the most recent technique, has been increasingly used in the $\mathrm{ICU}^{5}$ and is gaining acceptance for patients who receive invasive mechanical ventilation. ${ }^{6}$ The advantage of mechanical insufflation-exsufflation is that it applies negative pressure across both central and peripheral airways. Accordingly, this technique is probably the most physiologic reconstitution of natural cough, with the advantage, in patients who are intubated or tracheostomized, that there is no risk of abnormal airway collapse during exsufflation, whereas upper airway collapse can occur in patients who are not intubated. ${ }^{7,8}$ Another advantage seems to be patient preference for mechanical insufflationexsufflation over secretion suctioning, as observed in subjects with amyotrophic lateral sclerosis ${ }^{9}$ or spinal cord injury ${ }^{10}$ who were invasively mechanically ventilated.

In the current issue of RespiRatory CARE, de Camillis et $\mathrm{al}^{11}$ showed an interesting use of this technique. In their study, aspirated airway mucus was higher after the application of mechanical insufflation-exsufflation protocol compared with standard respiratory physiotherapy, including compression and positioning manual vibration maneuvers, and before tracheal tube suctioning in patients dependent on mechanical ventilation. The scarcity of controlled studies on this topic makes the presence of a control group all the more valuable in the demonstration that mechanical insufflation-exsufflation outperformed the other techniques. Moreover, the authors documented the decrease in airway resistance and the increase in dynamic compliance, which are expected and desired outcomes for endotracheal suctioning procedures according to the American Association for Respiratory Care Clinical Practice Guideline. ${ }^{12}$ Finally, although this study did not evaluate outcomes such as survival or ICU length of stay, it objectively demonstrated that a noninvasive technique of airway mucus clearance outperformed conventional tech- 


\section{EDITORIALS}

niques, followed by tracheal aspiration, which can lead to serious complications. These results are not only useful for patients in the ICU but also for patients on long-term mechanical ventilation through a tracheostomy tube in tertiary care centers ${ }^{13}$ and in home environment (although, in the latter, noninvasive techniques should be largely preferred).

Nicolas Terzi MD PhD

Service de Réanimation Médicale et INSERM Centre Hospitalier Universitaire Grenoble Alpes Grenoble, France

Hélène Prigent MD PhD

Frédéric Lofaso MD PhD

Service d'Explorations Fonctionnelles, Hôpital Raymond

Poincaré, Garches, France

INSERM

Université de Versailles

Saint Quentin en Yvelines, France

\section{REFERENCES}

1. Terzi N, Lofaso F, Masson R, Beuret P, Normand H, Dumanowski $\mathrm{E}$, et al. Physiological predictors of respiratory and cough assistance needs after extubation. Ann Intensive Care 2018;8(1):18.

2. Gobert F, Yonis H, Tapponnier R, Fernandez R, Labaune MA, Burle $\mathrm{JF}$, et al. Predicting extubation outcome by cough peak flow measured using a built-in ventilator flow meter. Respir Care 2017;62(12): 1505-1519.

3. Jelic S, Cunningham JA, Factor P. Clinical review: airway hygiene in the intensive care unit. Crit Care 2008;12(2):209.
4. Stiller K. Physiotherapy in intensive care: towards an evidence-based practice. Chest 2000;118(6):1801-1813.

5. Sánchez-García M, Santos P, Rodríguez-Trigo G, Martínez-Sagasti F, Fariña-González T, Del Pino-Ramírez Á, et al. Preliminary experience on the safety and tolerability of mechanical "insufflationexsufflation" in subjects with artificial airway. Intensive Care Med Exp 2018;6(1):8.

6. Toussaint M. The use of mechanical insufflation-exsufflation via artificial airways. Respir Care 2011;56(8):1217-1219.

7. Sancho J, Servera E, Díaz J, Marín J. Efficacy of mechanical insufflation-exsufflation in medically stable patients with amyotrophic lateral sclerosis. Chest 2004;125(4):1400-1405.

8. Andersen T, Sandnes A, Brekka AK, Hilland M, Clemm H, Fondenes $\mathrm{O}$, et al. Laryngeal response patterns influence the efficacy of mechanical assisted cough in amyotrophic lateral sclerosis. Thorax 2017;72(3):221-229.

9. Sancho J, Servera E, Vergara P, Marín J. Mechanical insufflationexsufflation vs. tracheal suctioning via tracheostomy tubes for patients with amyotrophic lateral sclerosis: a pilot study. Am J Phys Med Rehabil 2003;82(10):750-753.

10. Garstang SV, Kirshblum SC, Wood KE. Patient preference for inexsufflation for secretion management with spinal cord injury. J Spinal Cord Med 2000;23(2):80-85.

11. de Camillis MLF, Savi A, Rosa RG, Figueiredo M, Wickert R, Borges LGA, et al. Effects of mechanical insufflation-exsufflation on airway mucus clearance among mechanically ventilated ICU subjects. Respir Care 2018;63(12):1471-1477.

12. American Association for Respiratory C. AARC Clinical Practice Guidelines. Endotracheal suctioning of mechanically ventilated patients with artificial airways 2010. Respir Care 2010;55(6):758764.

13. Miske LJ, Hickey EM, Kolb SM, Weiner DJ, Panitch HB. Use of the mechanical in-exsufflator in pediatric patients with neuromuscular disease and impaired cough. Chest 2004;125(4):1406-1412. 